\title{
Investigating the post-complaint period by means of survival analysis
}

\author{
Bart Larivière*, Dirk Van den Poel \\ Department of Marketing, Ghent University, Hoveniersberg 24, 9000 Ghent, Belgium
}

\begin{abstract}
Firms increasingly view each contact with their customers as an opportunity that needs to be managed. The primary purpose of this article is to gain a better understanding of the customers' post-complaint period. Specific focus is placed on the impact of effective complaint handling on actual customer behavior throughout the time, whereas previous research has mainly focused on time-invariant or intentional measures. Survival analysis techniques are used to investigate the longitudinal behavior of complainants after their problem recovery. The proportionality assumption is tested for each explanatory variable under investigation. In addition, the impact for each variable is estimated by means of survival forests. Survival forests enable us to explore the evolution over time of the effects of the covariates under investigation. As such, the impact of each explanatory variable is allowed to change when the experiment evolves over time, in contrast to 'proportional' models that restrict these estimates to be stationary. Our research is performed in the context of a financial services provider and analyses the post-complaint periods of 2326 customers. Our findings indicate that (i) it is interesting to consider complainants since they represent a typical and rather active customer segment, (ii) furthermore, it is beneficiary to invest in complaint handling, since these investments are likely to influence customers' future behavior and (iii) survival forests are a helpful tool to investigate the impact of complaint handling on future customer behavior, since its components provide evidence of changing effects over time.
\end{abstract}

(C) 2005 Elsevier Ltd. All rights reserved.

Keywords: Data mining; Customer relationship management; Consumer complaint behavior; Actual customer behavior; Proportionality; Survival forests

\section{Introduction}

According to Keaveney (1995), the two major reasons why customers switch service providers are: (1) core service failures and (2) unfavorable service encounters with the company's personnel. When customers face a problem they may respond by exiting (= switching to another provider), loyalty (= staying with the supplier anticipating that 'things will get better') or voicing (=complaining to the firm or word-of-mouth to third-parties) (Levesque \& McDougall, 1996; Tax, Brown, \& Chandrashekaran, 1998). Unfortunately, it is only the tip of the iceberg that complains to the company (Stephens \& Gwinner, 1998) since dissatisfied customers tend to remain passive when experiencing a problem (Bougie, Pieters, \& Zeelenberg, 2003).

Customers who do not complain to the firm when dissatisfied are of special concern to management for several reasons. First, the company loses the opportunity to

\footnotetext{
* Corresponding author. Tel.: +32926435 24; fax: +329264 4279

E-mail address: bart.lariviere@ugent.be (B. Larivière).
}

0957-4174/\$ - see front matter (C) 2005 Elsevier Ltd. All rights reserved. doi:10.1016/j.eswa.2005.04.035 rectify the problem (Fornell \& Wernerfelt, 1988; Levesque \& McDougall, 1996) and to restore the customer's satisfaction level (Smith, Bolton, \& Wagner, 1999). Second, the firm's reputation can be damaged due to the negative word-of-mouth to friends, family or other people external to the customer's social circle, e.g. via newspapers (Bougie et al., 2003; Singh, 1988) which might result in the loss of prospects as well as current customers (Stephens \& Gwinner, 1998). Third, the firm is deprived of valuable information about its products and services (Fornell \& Wernerfelt, 1987) that is likely to improve the bottom-line performance and to prevent similar problems in the near future.

On the other hand, customers who complain and receive a proper response to their service failures are more likely to stay (e.g. Conlon \& Murray, 1996), to buy new products (e.g. Maxham III \& Netemeyer, 2003), to pay price premiums (e.g. Zeithaml, Berry, \& Parasuraman, 1996), to engage in favorable word-of-mouth and to recommend the company's services to others (e.g. Maxham III, 2001; Maxham III \& Netemeyer, 2002). Furthermore, they show higher shareof-wallet behavior (e.g. Bowman \& Narayandas, 2001) as well as higher commitment and trust towards the company (e.g. Tax et al., 1998). Finally, they are less vulnerable 
to switch (e.g. Bougie et al., 2003) and less likely to spread negative word-of-mouth to friends (e.g. Blodgett, Granbois, $\&$ Walters, 1993), or third-parties, such as other customers (e.g. Zeithaml et al., 1996). In sum, there is overwhelming evidence from previous research that successful complaint handling results in favorable customer outcomes. Additionally, in their study Fornell and Wernerfelt (1988) state that the return on investment in complaint management is likely to reach a 400 percent level.

When considering the consumer complaint behavior (CCB) literature, Stephens and Gwinner (1998) argue that much of the research is dominated by studies trying to understand why customers complain. In their paper, they provide an exhaustive list of investigated antecedents, including individual characteristics, attitudes, situational factors, the cost of complaining, etc. It is only since the last decade that literature has caught up by investigating the consequences of complaint handling (cf. previous paragraph). However, current knowledge is limited in providing insights regarding behavioral intentions or self-reported actual behavior measures resulting from critical incident technique studies in which the respondents are requested to think about their latest service switch (e.g. Keaveney, 1995). As is well known, data on actual behavior are often unavailable. Generally, the only data available are the selfreported intentions of the individuals who completed a postcomplaint questionnaire. Nevertheless, many authors argue that intentions are not always translated into subsequent behavior, since respondents typically do not have perfect information about changes that may occur in the future that may affect their behavior (Young, DeSarbo, \& Morwitz, 1998).

Unlike previous research, we investigate the impact of complaint handling on customers' actual behavior instead of intended behavior (=perceptual information). As a consequence, our research setting implies the need to link complaint data with complainants' behavioral information that is stored in transactional databases.

In this study, we decided to investigate the complainants 'next-buy' decision. We believe that an effective purchase reflects actual retention behavior (Larivière \& Van den Poel, 2004). In contrast to the studies that have investigated intended repeat purchasing behavior by questioning items such as 'In the near future, I intend to buy new products', we consider an actual product opening as a real and executed consequence of such an intention. The variable 'next-buy' expresses whether the customer has bought a new product during the observed period of analysis. The variable is operationalized as a time-varying dependent variable, in which the right-censoring situation is taken into account; that is, customers who have not bought a new product by the end of the observed period of analysis might do so in the future (that is, right-censoring).

Furthermore, we explicitly test whether the impact of complaint handling varies over time by means of survival forests, meaning that we allow for changes in the impact of complaint handling components on the customers' next-buy decision. In the context of complaints, it is plausible to assume that some effects, such as receiving compensation, fade out after a while. As such, we cannot use conventional 'proportional' models that assume stationary effects of the covariates throughout the observed window of observation.

In sum, we contribute to the existing CCB literature by presenting a framework of actual customer behavior in which we account for the right-censoring situation, and we explicitly test for the time-varying impact of explanatory variables by questioning the proportionality assumption.

The rest of this paper is organized as follows. In Section 2 we elucidate both the methodological underpinnings of the proportionality assumption and the survival forests technique. In Section 3, we present the data set and the explanatory variables under investigation. The study results and its implications are reported in Section 4. Section 5 concludes the paper and outlines some directions for further research.

\section{Methodology}

In this study we apply survival analysis techniques because our dependent variable is characterized by both a binary classification ('buy' or 'no buy') and a duration indicator for that purchasing (or censoring) event. First, we present the methodological underpinnings related to the proportionality assumption. Next, we elaborate on the survival forests technique that produces time-varying covariate estimates.

\subsection{Testing the proportionality assumption}

Survival analysis is a class of statistical methods modeling the occurrence and timing of events (in this case: the complainant's next-buy decision).

Survival data have the following form:

$\left\{\left(c_{n}, t_{n}, x_{n}\right), \quad n=1, \ldots, N\right\}$

where $n$ represents the index to the $2326(N)$ complainants under investigation in this study; $c_{n}$ is the status (or binary classification) indicator which represents whether the complainant repurchased within the period of analysis; $t_{n}$ is the duration indicator and represents the time to the event or the censoring time (that is, for the customers who did not experience the event of buying within the period of analysis); $x_{n}$ is the vector of covariates for each customer $n$, and refers to the complaint handling and control explanatory variables in this study (cf. Section 3.2). The goal of survival analysis is to trace the effects of the covariates on the times to the event; or in this study: the impact of complaint handling on the duration to repurchase.

The field of survival analysis is dominated by the Cox proportional hazard model (Stare, Harrell, \& Heinzl, 2001). 
The technique is widely used due to its convenient advantages: the technique (i) allows for incorporating time-varying covariates and both discrete and continuous measurements of event times, (ii) can handle observations that did not experience the event (that is, censored observations) and (iii) appears to be very robust and requires few assumptions (Kumar \& Westberg, 1997; Van den Poel \& Larivière, 2004).

The Cox proportional hazard for customer $n$ at time $t$, given his vector of covariates $x_{n}$ can be written as follows:

$h_{n}\left(t, x_{n}\right)=h_{0} \exp \left(\beta x_{n}\right)$

in which $h_{0}$ represents the baseline hazard.

Despite its convenient advantages, proportional hazard models imply the important key assumption of 'proportionality'; which is often overlooked when applying the technique (Boucher \& Kerber, 2001; Moitra \& Lee, 1993; Therneau \& Grambsch, 2000). Proportionality means that the hazard for any individual $i$ is a fixed proportion $\gamma_{i j}$ of the hazard of any other individual $j$ (hence the name 'proportional hazard'):

$\gamma_{i j}=\frac{h_{i}\left(t, x_{i}\right)}{h_{j}\left(t, x_{j}\right)}=\frac{h_{0} \exp \left(\beta x_{i}\right)}{h_{0} \exp \left(\beta x_{j}\right)}=\exp \left\{\beta\left(x_{i}-x_{j}\right)\right\}$

As a consequence, during estimation the baseline hazard $h_{0}$ cancels out, which is often referred to as the semiparametric estimation of the hazard model.

In this study, we explicitly test for the proportionality assumption with respect to each explanatory variable. In order to do so, we follow Allison's (1999) suggested approach to compare the graphs of smoothed hazard functions for each covariate's stratum; parallel curves provide evidence for proportionality. Smoothed hazard functions are produced by means of a kernel smoothing method, as described by Ramlau-Hansen (1983).

\subsection{Estimating covariates by means of survival forests}

In case the proportionality assumption is violated, one needs to use other methods that do not impose restrictions with regard to that assumption. In this study, we choose the novel technique of survival forests proposed by Breiman (2002).

Survival forests represent the newest extension of Breiman's random forests technique, next to the classification and regression forests (e.g. Larivière and Van den Poel, 2005). The software can be downloaded free of charge from the internet (Breiman, 2003). In his software Breiman proposes two methods for using survival forests: that is, 'correlations over time' and 'time fitting Cox models'. 'Correlations over time' compute the correlation between $\log \left(\hat{S}\left(t_{k}, x_{n}\right)\right)$ and each of the covariates at each event time point $t_{k}$; in which $\hat{S}$ represents the estimated survival probability. If a Cox model fits the data (that is, the 'proportionality' assumption is satisfied), these correlations should be constant over time.
With respect to 'time fitting Cox models', at each event time $t_{k}$ the following two equations (3) and (4) are defined:

$y_{n}=L\left(t_{k}, x_{n}\right)$

$f(n, t(k), \beta(k))=t(k) \exp \left(\beta(k) x_{n}\right)$

in which

$L\left(t_{k}, x_{n}\right)=-\log \left(\hat{S}\left(t_{k}, x_{n}\right)\right)$

and, in which $\beta(k)$ refers to estimates for the coefficients of the covariates $x$ at each duration time $k$ and $t(k)$ represents the estimate of the integral of the baseline risk. In fact, the right hand side of Eq. (4) is similar to the Cox expression in Eq. (2), with the difference that $t(k)$ and $\beta(k)$ need to be determined. Analogously to random forests (Breiman, 2001), a collection of decision trees (i.e. a forest) is grown to estimate $\hat{S}\left(t_{k}, x_{n}\right)$. This is done by minimizing:

$\sum_{n}\left(y_{n}-f(n, t(k), \beta(k))\right)^{2}$

If a Cox model fits the data, the $\beta(k)$ should be constant in time.

In this study we opt for the 'time fitting Cox models' tool, since the plot of $\beta(k)$ enable to investigate the impact of the covariates over time; which is the primary purpose of this study.

\section{Empirical study}

A Belgian financial services provider delivered the data for this study. Its customers have the opportunity to express their complaints to the company whenever they perceive a problem with respect to the products and services they possess. When a customer experiences a (product or) service failure, he has the possibility to formulate his complaint either directly towards the company's complaint department or to his banking agent who will pass it on to the complaint department. In the latter scenario, it is also plausible that the intermediary is capable himself of recovering the problem, and consequently, the service failure would not reach the complaint department. As such, with respect to the complaints expressed to intermediaries, we assume that especially the more 'complicated' failures will be handled by the complaint department.

The complaint handling department of the company under investigation started collecting (and storing) complaint information in January 2000. Our research setting implies the link with the data warehouse information needed to investigate the customer's subsequent actual behavior. Therefore, we decided to analyze the complaints expressed from January 2000 till 1 February 2003, since the latest release date of data warehouse information is 1 February 2004; as such we ensure a response period (to buy another product) of minimum 12 months for every complainant. Fig. 1 depicts the timeline for this study. 


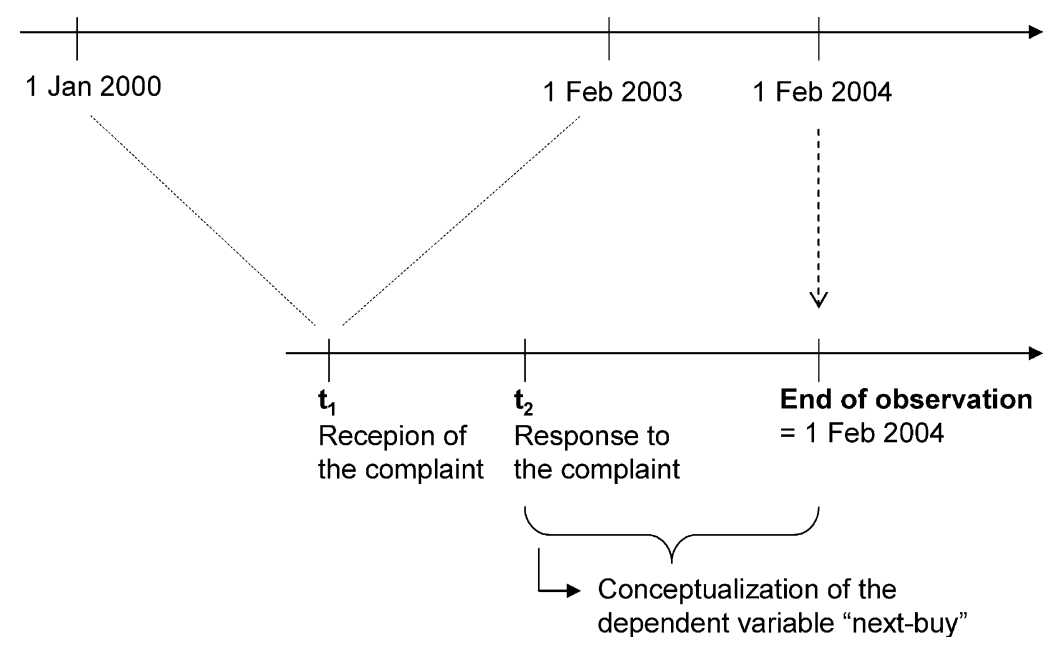

Fig. 1. Period of analysis.

\subsection{Conceptualization of the dependent variable}

In this study we investigate the customers' 'next-buy' decision as the focal actual behavior dependent variable. For each customer, the dependent variable receives two indictors: a status indicator and a duration indicator. The status indicator represents the binary classification and expresses whether the complainant has bought a new product in the subsequent period (that is, between $t_{2}$ and 1 February 2004 in Fig. 1); the duration indicator expresses how long it takes before the customer has bought that product. As shown in Fig. 1, the customers under investigation are allowed to have different duration times, since their entry times range from 1 January 2000 to 1 February 2003 as well as their buying dates may differ. More specifically, the complainants who repurchase after their service recovery receive the value of ' 1 ' for their buy status indicator and receive the time elapsed since $t_{2}$ until the date of buying the new product as duration indicator. On the other hand, the customers who did not repurchase (that is, the right-censored cases) receive the value of ' 0 ' for the status indicator and their duration indicator is determined by calculating the time between $t_{2}$ and the end of observation (that is, 1 February 2004). All duration terms are expressed in months.

\subsection{Explanatory variables}

The major purpose of this study is to investigate the impact of complaint handling on subsequent actual customer behavior. In the next paragraphs we present the explanatory variables under investigation in this study.

\subsubsection{Complaint handling variables}

To date, many firms are not well informed on how to deal successfully with service failures or the impact of complaint handling strategies (Tax et al., 1998). Furthermore, the CCB literature suggests that customers are often more dissatisfied by an organization's failure to recover than by the service failure itself (Keaveney, 1995; Smith et al., 1999). With the complaint handling variables of this study we emphasize the latter attempt. It is our intention to investigate their timevarying impact on the customer's next-buy decision over time.

When considering previous complaint studies that analyzed the impact on future intended behavior, it is clear that the investigation of 'perceived justice' or 'satisfaction with recovery' dominates the literature, whereas other antecedents of customer outcome that are related to the complaint handling encounter are often ignored in previous research (e.g. Blodgett et al., 1993; Maxham III, 2001; Maxham III \& Netemeyer, 2002; Tax et al., 1998; Zeithaml et al., 1996). A notable exception is the study by Conlon and Murray (1996) who examine the impact of (1) the type of explanation, (2) the presence of compensation, (3) problem severity and (4) the speed of the company's reply on both customers' satisfaction level with the explanation and their willingness to do business with the company in the near future.

With respect to the complaint handling variables that are analyzed in this study, we use the information that is stored by the complaint handling department during the service recovery process. All complaint handling variables are gathered at $t_{1}$ or $t_{2}$ (cf. Fig. 1). The next paragraphs present the complaint handling variables that are investigated in this study (the information between brackets indicates whether the information is gathered at $t_{1}$ or $t_{2}$ ). Table 1 summarizes the explanatory variables of this study, whereas Table 2 reports their intercorrelations.

3.2.1.1. Severity of the complaint $\left(t_{1}\right)$. Fear of opportunistic customers is an important reason why firms are reluctant towards customers' demands (Wirtz \& Kum, 2004). In the context of complaints, it is realistic that not every service failure is equally severe or even justified. In their study, Conlon and Murray (1996) analyzed two surrogate 
Table 1

Explanatory variables under investigation in this study

\begin{tabular}{ll}
\hline Complaint handling variables & \\
Severity of the complaint & Justification \\
Organization's fault & org_fault \\
Speed of the company's reply & reply_d1 \\
& reply_d2 \\
& reply_d3 \\
& reply_d4 \\
Financial compensation & fin_comp \\
Satisfaction with recovery & sat_rec \\
Control variable & \\
Recency & Recency \\
\hline
\end{tabular}

measures of problem severity: (1) the price of the product and (2) the level of dissatisfaction the problem generated. They found that the former surrogate had a negative impact on both the customers' satisfaction with the explanation and their repatronage intentions, whereas the latter surrogate revealed no significant impact on both dependent variables. In this study, we test for the severity of the complaint, by using a 'justification' judgment. When the complaint handling department of the company under investigation receives a complaint they judge the severity of the service failure by reflecting whether the complaint is justified. In this study, we investigate the variable 'justification' which takes the value of ' 1 ' when the complaint is justified. Although the severity of a complaint refers to an employee's judgment in this study, we believe that the variable is likely to represent an important antecedent of subsequent behavior, since it is plausible to assume that the response of the company will be influenced by its perception about the fairness of the complaint.

3.2.1.2. Organization's fault $\left(t_{1}\right)$. Besides the severity of a complaint, the employees who recover the service failure also gather information about who is responsible ('guilty') for the problem. The variable 'org_fault' represents whether the problem is caused by the company. To the best of our knowledge, no research has yet examined the impact of such an information item on customer's subsequent behavior. However and somewhat related, Conlon and Murray (1996) have investigated the impact of explanations in which a company accepted responsibility for the service failure and found a favorable impact on customer intentions.

3.2.1.3. Speed of the company's reply $\left(t_{2}\right)$. The speed of the company's reply refers to time it took to recover from the service failure. Considering the timeline in Fig. 1, the variable equals to the number of dates between $t_{1}$ and $t_{2}$. In this study we analyze four dummy variables that encompass the speed of the recovery process: 'reply_d1', 'reply_d2', 'reply_d3', 'reply_d4'. The four dummy variables represent whether the complaint has been solved within the same day, from 1 to 3 days, from 4 to 7 days and from 7 to 14 days, respectively. When all four variables have the value of ' 0 ', it means that it took more than 14 days to solve the problem. Also previous research has investigated the impact of the swiftness of replying to the problem. In their study, Conlon and Murray (1996) approached the speed of the company objectively and perceptually, but only found a significant impact for the latter conceptualization. In our study, we only consider the 'objective' time needed to recover from the problem, since questionnaire data are unavailable.

3.2.1.4. Financial compensation $\left(t_{2}\right)$. Some complainants of the company under investigation received a financial indemnification for their complaint, whereas some other complainants made no claim to receive any form of compensation along with the answer to their service failure. In their study, Conlon and Murray (1996) found that customers who received coupons report greater willingness to do business with the company in the future. In this study, we investigate the dummy variable 'fin_comp' that indicates whether the complainant received financial compensation for his service failure.

3.2.1.5. Satisfaction with recovery $\left(t_{2}\right)$. Many researchers have investigated the impact of satisfaction with recovery on customer's behavioral intentions. Previous research findings reveal that satisfaction with the complaint process stimulates the retention proneness of the customers, as well as their likelihood to recommend and to spread favorable word-ofmouth (Bougie et al., 2003; Bowman \& Narayandas, 2001; Levesque \& McDougall, 1996; Maxham III, 2001;

Table 2

Intercorrelations

\begin{tabular}{|c|c|c|c|c|c|c|c|c|}
\hline \multirow[t]{2}{*}{ Variables } & \multicolumn{8}{|c|}{ Intercorrelations } \\
\hline & 2 & 3 & 4 & 5 & 6 & 7 & 8 & 9 \\
\hline 1. justification & 0.556 & 0.214 & 0.003 & -0.082 & -0.052 & 0.249 & 0.080 & 0.013 \\
\hline 2. org_fault & & -0.035 & 0.068 & 0.000 & -0.003 & 0.416 & -0.013 & -0.016 \\
\hline 3. reply_d1 & & & -0.273 & -0.224 & -0.212 & -0.121 & 0.162 & -0.074 \\
\hline 4. reply_d2 & & & & -0.217 & -0.205 & -0.052 & 0.000 & -0.006 \\
\hline 5. reply_d3 & & & & & -0.169 & 0.023 & -0.033 & 0.024 \\
\hline 6. reply_d4 & & & & & & 0.099 & -0.164 & 0.043 \\
\hline 7. fin_comp & & & & & & & -0.114 & 0.003 \\
\hline 8. sat_rec & & & & & & & & -0.037 \\
\hline 9. Recency & & & & & & & & \\
\hline
\end{tabular}


Maxham III \& Netemeyer, 2002; Tax et al., 1998; Zeithaml et al., 1996). In this study, we investigate the impact of satisfaction with recovery on customer's actual buying behavior. The satisfaction indicator is gathered at the time of formulating a reply to the customer (that is, $t_{2}$ in Fig. 1). The variable 'sat_rec' is a dummy variable reflecting the employee's perception of the customer's reaction with regard to the complaint answer; that is, when the employee perceived that the customer agreed with the final solution, he coded the corresponding complaint record with a 'satisfied = yes' label. We believe that 'sat_rec' represents a good proxy for the customers' satisfaction level with respect to the recovery of his complaint.

\subsubsection{Control variable}

Since our research investigates actual buying behavior instead of repeat purchase intentions, which implies the necessity to combine complaint records with the company's data warehouse, we decided to control for the recency of the customer's previous purchase. In the context of complaints, it is plausible to assume that some customers perceive failures with respect to the products they just acquired: as such, investigating a next-buy decision longitudinally without considering this type of information would result in biased conclusions. In this study, we explicitly account for the variable 'recency' and we hypothesize that complainants who just acquired a new product are less likely to buy another one, although they might be satisfied about their problem recovery. The variable 'recency' represents the time elapsed until $t_{1}$ (cf. Fig. 1) and is expressed in months.

\section{Findings}

The next paragraphs contain the findings of the study. First, we report survival estimates for satisfied versus dissatisfied complainants, and we benchmark them against a random sample of non-complainants. Then, we present the findings of the proportionality investigation and the time-varying parameter estimates resulting from the survival forests. Finally, we suggest how one can approximate non-proportionality in conventional Cox regression.

\subsection{Complainants versus non-complainants}

Since our research setting integrates complaint handling records with data warehouse information, we have the possibility to analyze the actual behavior of non-complainants. As in previous research (e.g. Zeithaml et al., 1996) we compare three groups: (i) no complaint, (ii) complaint with satisfactory recovery and (iii) complaint with unsatisfactory recovery. We randomly selected 2500 customers who did not complain within the period of analysis (that is, between 1 January 2000 and 1 February 2003, cf. Fig. 1) and we observed them for the same period with respect to their next-buy behavior.

We investigate the timing of the next-buy decision for the three groups by means of Kaplan-Meier survival estimates. The Kaplan-Meier estimator-also known as the product-limit estimator-is the most widely used method for estimating survival functions (Efron, 1988). Survival probabilities are presented as a survival curve. The 'curve' is a step function with sudden changes in the estimated probability corresponding to times at which events are observed (Bland \& Altman, 1998). In Fig. 2 we present survival probabilities for the three groups. Our findings indicate significant differences with respect to the three repurchase times since the Log-Rank statistics report $p$ values between $<0.0001$ and 0.0009 for each $2 \times 2$ comparison.

It is clear from Fig. 2 that satisfied complainants experience shorter repurchase times than their opponents who are dissatisfied about the service recovery, since the survival line of the former group decreases faster toward the horizontal axis. Survival probabilities represent 'the likelihood of surviving' or in this context: 'the likelihood of not experiencing the purchase incident'. Therefore, lower survival rates stand for higher repeat-purchase behavior. Hence, our study reveals the logical relationship between satisfied and dissatisfied complainants with respect to their actual repurchase behavior and finds support for previous $\mathrm{CCB}$ studies that were restricted to examine behavioral intentions.

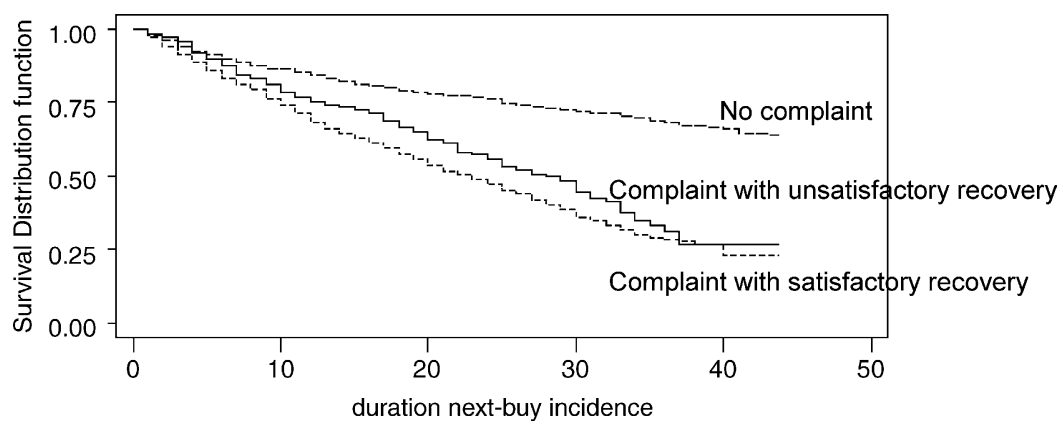

Fig. 2. Survival probabilities for (dis)satisfied complainants versus non-complainants. 
A second, and more intriguing finding of Fig. 2 concerns the fact that non-complainants report the lowest repurchase behavior. As such, complainants with an unsatisfactory service recovery show evidence of higher repeat-purchase behavior than the group of non-complainants. Generally, non-complainants consist of customers who do not experience a service problem as well as customers who do not complain about the problem they encounter. A possible explanation might be that complainants represent more 'active' customers who are not only more inclined to complain when they experience a service failure, but also more likely to buy (even when they are dissatisfied about the service recovery) compared to the more 'passive' customers who do not buy as often and are less likely to communicate with the company. As such, we assume that (i) 'being an active customer' has a stronger impact on future behavior than the satisfaction level with the service recovery and that (ii) complaining is a result of being active. Further research is warranted on this issue.
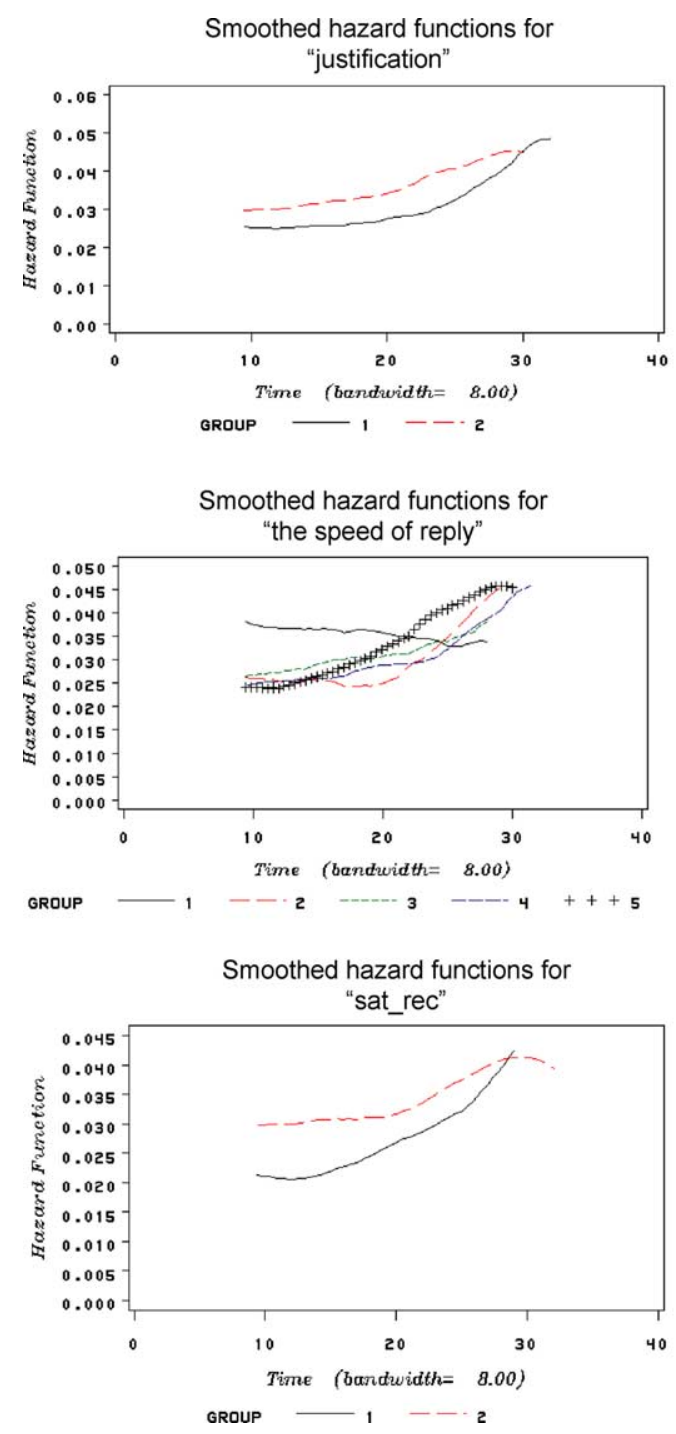

Fig. 3. Graphs of smoothed hazard functions for the explanatory variables.

\subsection{Investigation of the proportionality assumption}

In order to test the proportionality assumption for each explanatory variable, we investigate the smoothed hazard functions for each covariate's stratum as suggested by Allison (1999). With respect to the 'recency' variable we decided to create an 'aggregated' stratum variable 'rec_categ' since the original variable ('recency') contains more than two (or $n$ distinct category) values. We decided to categorize the 'recency' variable into four groups based on its quartiles. As such, the stratum variable 'rec_categ' contains four different values; that is, representing the four quartiles. In Fig. 3 we present the plots for each explanatory variable.

As stated in the methodology section (cf. Section 2.1): parallel curves provide evidence for proportionality. It is clear from Fig. 3 that the proportionality assumption is not satisfied for the complaint handling and control variables in this study. Hence, we find evidence that the impact of
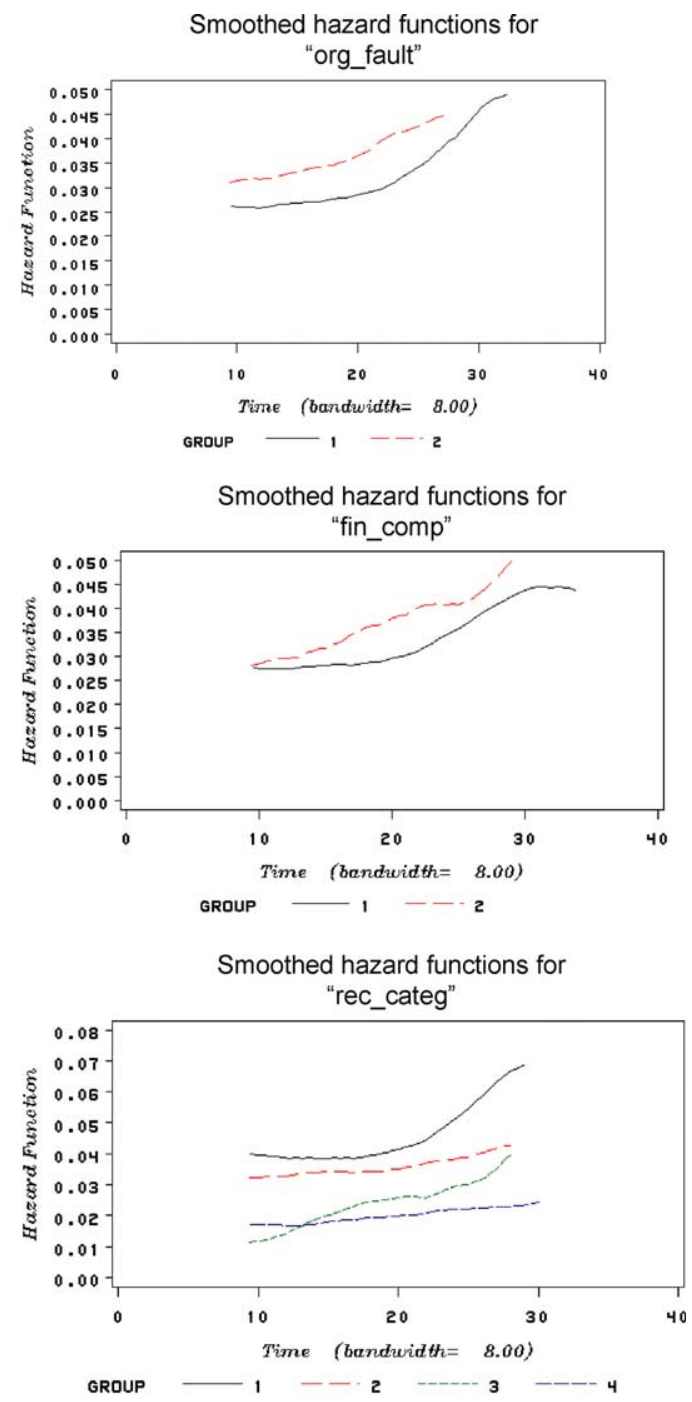
complaint handling on subsequent behavior varies over time, such that one needs techniques that can handle nonproportionality in order to investigate the longitudinal impact of the explanatory variables on the complainants' next-buy decision.

\subsection{The impact of the explanatory variables throughout the time}

In the previous section we found evidence that the effects of the explanatory variables vary over time, which implies that conventional proportional hazard models are less attractive to fit our data since they restrict these effects to be stationary.

By means of survival forest, we are able to fit Cox models at each time $t_{k}$, meaning that the parameter estimates for the covariates are allowed to change at each time $t_{k}$. (cf. Section 2.2). In sum, the use of survival forests enables us to investigate the time-varying impact of each of the explanatory variables on the dependent variable of this study: that is, the complainant's next buy decision. Table 3 and Fig. 4 summarize the output of the survival forests: Table 3 reports the average parameter estimates for each explanatory variable, whereas Fig. 4 presents the parameter estimates throughout the time.

In is clear from Table 3 that all complaint variables have a positive parameter estimate, meaning that they have a positive association with the dependent variable. On the other hand, for the 'recency' variable we observe a negative relationship with the complainant's next buy decision. With respect to the time-varying effects of the explanatory variables we observe the most dramatic changes for the 'reply_d1', 'recency' and 'fin_comp' variables (cf. Fig. 4). Hence, our findings highlight the benefits of using non-proportional estimation techniques when analyzing survival data, since the impact of some explanatory variables are likely to change when the experiment evolves in time.

In the next paragraphs, we elaborate on the direction of the covariate's impact and we examine its time-varying impact on the next-buy decision, by exploring the plots of the $\beta(k)$ (cf. Section 2.2) in Fig. 4.

Table 3

Average survival forests estimates for the explanatory variables

\begin{tabular}{lc}
\hline Variables & Average $\beta(k)$ \\
\hline Justification & 0.028 \\
org_fault & 0.045 \\
reply_d1 & 0.300 \\
reply_d2 & 0.039 \\
reply_d3 & 0.269 \\
reply_d4 & 0.010 \\
fin_comp & 0.059 \\
sat_rec & 0.040 \\
Recency & -0.589 \\
\hline
\end{tabular}
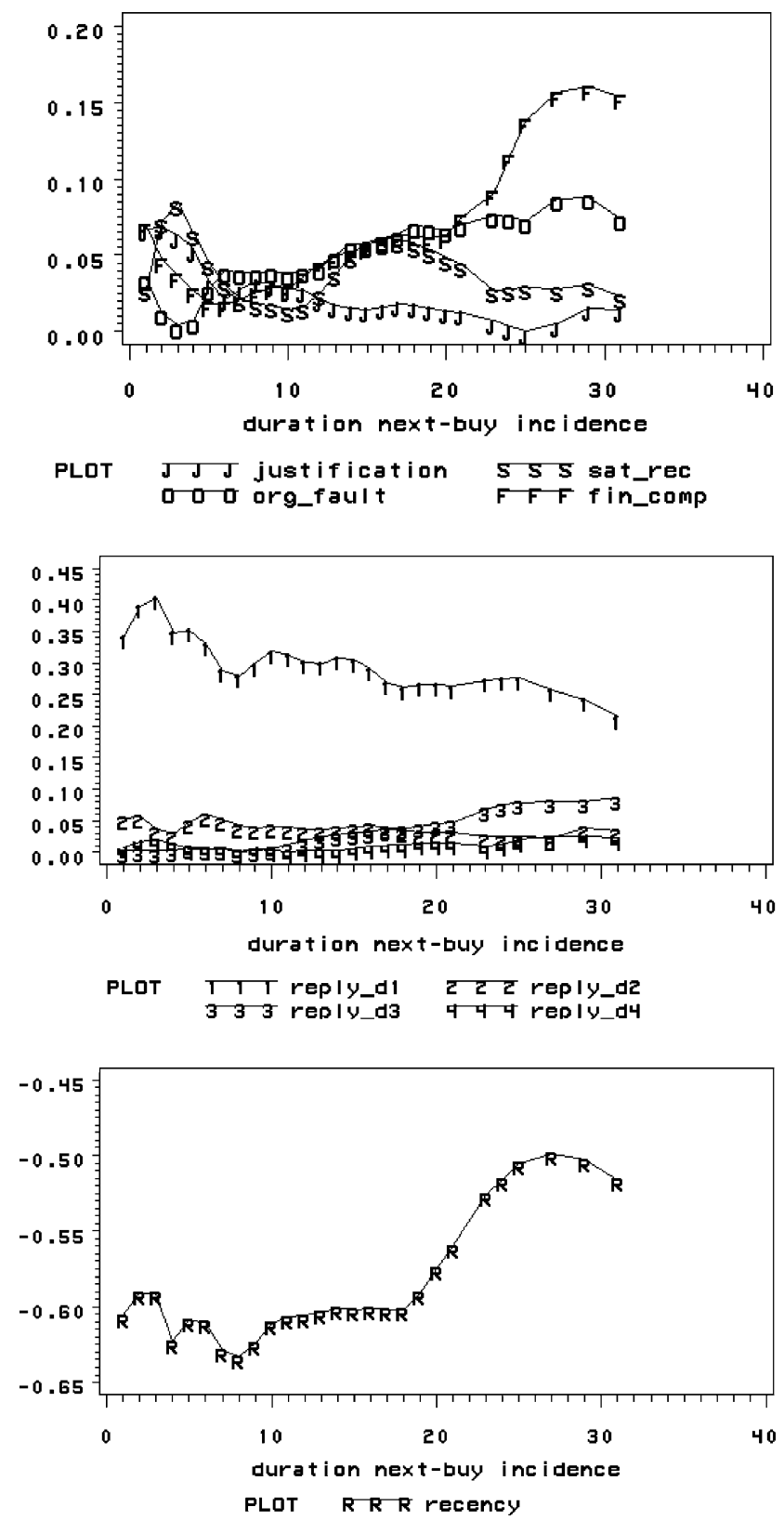

Fig. 4. Time-varying parameter estimates of the explanatory variables by means of survival forests.

\subsubsection{Severity of the complaint}

The variable 'justification' has a positive average parameter estimate and its impact is decreasing within the first 6 months after the service recovery, followed by a more stationary impact after this 6-month period. With respect to the 'justification' variable we hypothesized a positive relationship with the complainants' next-buy decision since we assumed more favorable recoveries for more justified service failures. The survival forests findings support this hypothesis. Especially during the first 6 months a 'better' complaint recovery results in higher repeatpurchase behavior. Afterwards the effect is fading out (but still positive). 


\subsubsection{Organization's fault}

The complainants who expressed a service failure which is due to the company's fault reveal a decrease in subsequent purchase behavior within the first 3 months, followed by a slight increase. Furthermore, the average parameter estimate is positive. As such, our findings indicate that failures caused by the company may result in negative customer outcomes since these customers are likely to experience anger. Nevertheless, an appropriate service recovery is likely to absorb this negative feeling and to restore the negative customer behavior into a favorable one. As hypothesized for the 'justification', we assumed that customers who experienced an 'organization's fault' service failure received a more favorable response to their complaint. Our survival forests findings indicate that such responses meet their purpose after the third month.

\subsubsection{Speed of the company's reply}

The four dummy variables 'reply_d1', 'reply_d2', 'reply_d3' and 'reply_d4' all have a positive average parameter estimate. The former variable ('reply_d1') has the strongest impact, whereas the other variables are hovering close to the horizontal axis. The variable 'reply_d1' expresses whether the complaint is recovered within the same day. It is clear from Fig. 4 that an immediate reply to the customer's service failure is very important. Although, its impact is decreasing within certain periods, the variable supports the hypothesis that the speed of the company's reply has a positive impact on the complainant's subsequent behavior.

\subsubsection{Financial compensation}

Table 3 and Fig. 4 reveal that (i) financial compensations for service failures result in favorable repeat-purchase behavior and that (ii) its impact is increasing over time. As such, we find support for this conclusion in the study by Conlon and Murray (1996) who found that customers who received coupons report greater willingness to do business with the company in the future.

\subsubsection{Satisfaction with recovery}

With respect to our 'sat_rec' variable we find evidence of a positive impact on actual purchase behavior. Furthermore, we observe an increasing positive impact during the first 3 months after the service recovery, followed by a lower and slightly fluctuating impact in the subsequent period.

\subsubsection{Recency}

In this study, we explicitly control for the impact of the customer's previous purchase (cf. Section 3.2.2). Contrary to what was hypothesized we find that complainants who recently bought a new product are even more likely to buy another one in the subsequent period, since the average parameter estimate is negative. As a consequence, we find evidence that some complainants belong to the most 'active' segment of the company's customer base: they are constantly buying new products, and they complain whenever they perceive a problem. Furthermore, Fig. 4 indicates that this negative impact is decreasing over time, meaning that the 'interactive' customers are more likely to buy sooner than later.

In the previous sections, we discussed the parameter estimates of the explanatory variables under investigation in this study. Since survival forests are a rather novel technique, we decided to additionally test for the impact of multicollinearity in this study. As well-known, multicollinearity (i) makes the parameter estimates unreliable and (ii) inflates the standard errors (Leeflang et al., 2000; Morrow-Howell, 1994). Table 2 revealed some rather high intercorrelations between 'org_fault' and 'justification' (0.556) and between 'org_fault' and 'fin_comp' (0.416). Therefore, we decided to run an extra survival forests model without the variable 'org_fault'. The findings of this analysis are reported in Table 4.

It is clear from Table 4 that the level of intercorrelations in this study does not dramatically change the parameter estimates (similar findings were found when plotting the parameter estimates over time). Additionally, we simulated a new variable 'rec_corr' which correlates 0.97 with the variable 'recency' in order to better understand the impact of higher intercorrelations on the time-varying parameter estimates produced by survival forests. The results in Table 4 reveal that the introduction of the highly correlated 'rec_corr' variable dramatically changes the parameter estimate of the variable 'recency' which increases by 0.309 . As a consequence, our additional findings indicate that survival forests also suffer from the effects of multicollinearity (like traditional statistical techniques), such that researchers need to be cautious when interpreting the survival forests estimates of highly intercorrelated variables.

\subsection{Approximating non-proportionality in cox regression}

In this section we elaborate on how researchers can approximate non-proportionality in Cox regression and by doing so, we demonstrate the pernicious consequences of applying Cox regression without testing (and controlling) for proportionality in the analysis sample.

Table 4

Testing for the impact of multicollinearity

\begin{tabular}{lcc}
\hline Variables & \multicolumn{2}{c}{ Multicollinearity tests } \\
\cline { 2 - 3 } & Average $\beta(k)$ & Average $\beta(k)$ \\
\hline Justification & 0.026 & 0.034 \\
org_fault & $/$ & 0.057 \\
reply_d1 & 0.319 & 0.285 \\
reply_d2 & 0.054 & 0.029 \\
reply_d3 & 0.023 & 0.014 \\
reply_d4 & 0.024 & 0.016 \\
fin_comp & 0.060 & 0.042 \\
sat_rec & 0.034 & 0.034 \\
Recency & -0.587 & -0.280 \\
rec_corr & $/$ & -0.320 \\
\hline
\end{tabular}


Table 5

Approximating non-proportionality in Cox regression

\begin{tabular}{lrll}
\hline Cox regression models & & & \\
\hline Variable & $\begin{array}{l}\text { Parameter } \\
\text { estimate }\end{array}$ & $\operatorname{Pr}>$ ChiSq & Hazard ratio \\
\hline $\begin{array}{l}\text { Model 1 } \\
\text { fin_comp }\end{array}$ & 0.08290 & 0.28 & 1.086 \\
Model 2 & & & \\
fin_comp & -0.01837 & 0.84 & 0.982 \\
fin_comp_period & 0.34422 & 0.03 & 1.411 \\
\hline
\end{tabular}

In general, when applying conventional proportional hazard models one assumes that the estimates of the explanatory variables do not vary over time. By means of an example we first run a Cox regression with 'fin_comp' as independent variable (cf. Model 1 in Table 5). Next, we create two new variables: A dummy variable 'period' that is coded as ' 1 ' when the duration time is between 15 and 26 months (and coded as ' 0 ' in the other case) and an interaction variable 'fin_comp_period' which is the product of the former dummy variable and 'fin_comp'. In Model 2, the new interaction variable 'fin_comp_period' is introduced into the Cox model. In sum: in Model 1, we apply a proportional hazard model in which we test for the impact of 'fin_comp' and in which we neglect the proportionality assumption; on the other hand, in Model 2 we explicitly account for a 'sensitive' period for which we observed a greater impact of a financial compensation. The period ranging from 15 to 26 months is determined based on the smoothed hazard functions (cf. Fig. 3) as well as the survival forests graphs (cf. Fig. 4) with respect to the 'fin_comp' variable; Fig. 3 revealed an increased difference between the two graphs within this period, whereas Fig. 4 showed the dramatic increase of the value for the corresponding parameter estimate. In Table 5 we report the results of the two models.

It is clear from Table 5 that the impact of 'fin_comp' is not statistically significant in Model 1. On the other hand, in Model 2 we observe a significant impact of the 'fin_comp_ period' variable, meaning that financial compensation has a significant and positive impact on customers' subsequent buying behavior within this time period. In sum, our findings reveal the importance of both (i) testing for proportionality and (ii) accounting for it during the estimation process, since neglecting proportionality is likely to bias the results, and as consequence, might lead to wrong managerial decisions and actions.

\section{Conclusion and further research directions}

This study investigates the post-complaint period of the customers of a financial services provider. Unlike previous CCB studies that mainly focused on behavioral intentions, we analyze the impact of complaint handling on actual purchase behavior. Moreover, the dependent variable (that is, the complainant's next-buy decision) is conceptualized longitudinally by means of a status and a duration indicator, such that we are able to account for right-censored observations. The primary purpose of this article is to gain a better understanding of the role of a company's complaint handling department by investigating the impact of its components on customers' subsequent behavior. In this study, we investigate five complaint handling variables: severity of the complaint, organization's fault, speed of the company's reply, financial compensation and satisfaction with recovery. Furthermore, we explicitly control for the recency of the complainant's previous purchase. We apply survival analysis techniques to investigate the longitudinal behavior of the complainants after their service recovery. First, the proportionality assumption is tested for each covariate by means of smoothed hazard functions. Our findings provide evidence that the effects of the explanatory variables in this study vary over time (that is, nonproportionality) which implies that conventional 'proportional' hazard models are less attractive to fit our data, since they restrict these estimates to be stationary. Therefore, we decided to use the novel technique of survival forests, since the technique enables us to fit Cox regression at each observed event time, such that the estimates are allowed to vary over time. To the best of our knowledge, this study is the first in adopting the survival forests technique for analyzing a customer relationship management (CRM) topic.

\subsection{A number of interesting findings emerge from our study}

First, it is clear that complainants represent a rather 'active' customer segment, since our findings indicate that customers dissatisfied with the service recovery are even more likely to repurchase than non-complainants. Moreover, our findings provide evidence that complainants who just bought another product, are more inclined to repurchase in the near future, since the parameter estimate of the control variable 'recency' reveals a negative and decreasing impact on the customer's next-buy decision. For future research it offers an opportunity to elaborate on the active customer segment. Although they might be dissatisfied about their problem recovery, they are still likely to continue their buying behavior. A first avenue for further research concerns a profound investigation of the customer's activeness-communication encounter (e.g. complaining)—future behavior triad.

Second, besides the intriguing 'non-complainant' versus 'complaint with unsatisfactory recovery' findings of this study, our results confirm previous findings in the CCB literature: complainants who are satisfied about their service failure report higher repeat-purchase behaviors than dissatisfied customers. Similar findings result from the other complaint handling variables. With respect to the most important complaint handling variables, it is clear from Table 3 and Fig. 4 that a fast problem recovery and a financial compensation have the greatest impact on the complainant's subsequent behavior. As such, we can 
ascertain the value of a complaint handling department with respect to favorable customer behavior.

Third, it is clear from our analyses that the impact of complaint handling variables on customers' future behavior is likely to change over time. In this study, we observed the most dramatic changes for the speed of the reply, the financial compensation and the recency of the latest purchase. Even though a Cox regression can be adapted to take into account violations of the proportionality assumption (cf. Section 4.4), survival forests provide a more general approach by investigating the impact of covariates at each event time point. In doing so, the user does not need to know in advance nor to specify (i) for which periods the effect of each covariate differs as well as (ii) their exact time frame. As such, we conclude that the survival forests technique is a promising tool for analyzing survival data.

\section{Acknowledgements}

The authors would like to thank the anonymous company and its complaint handling department that supplied the data to perform this research study. Moreover, we are grateful to Leo Breiman for the public availability of the survival forests software.

\section{References}

Allison, D. A. (1999). Logistic regression using the SAS ${ }^{\circledR}$ System: Theory and application. Cary, NC: SAS Institute.

Bland, J. M., \& Altman, D. G. (1998). Survival probabilities (The KaplanMeier method). British Medical Journal, 317(7172), 1572-1573.

Blodgett, J. G., Granbois, D. H., \& Walters, R. G. (1993). The effects of perceived justice on complainants' negative word-of-mouth behavior and repatronage intentions. Journal of Retailing, 69(4), 399-428.

Boucher, K. M., \& Kerber, R. A. (2001). The shape of the hazard function for cancer incidence. Mathematical and Computer Modelling, 33(12/13), 1361-1375.

Bougie, R., Pieters, R., \& Zeelenberg, M. (2003). Angry customers don't come back: They get back: The experience and behavioral implications of anger and dissatisfaction in services. Journal of the Academy of Marketing Science, 31(4), 377-393.

Bowman, D., \& Narayandas, D. (2001). Managing customer-initiated contacts with manufacturers: The impact on share of category requirements and word-of-mouth behavior. Journal of Marketing Research, 38, 281-297.

Breiman, L. (2001). Random forests. Machine Learning, 45(1), 5-32.

Breiman, L. (2002). Software for the masses, in: Wald Lectures, Meeting of the Institute of Mathematical Statistics, Banff, Canada, URL: www. berkeley.edu/ breiman.

Breiman, L. (2003). How to use survival forests, Department of Statistics, University of California, Berkeley, URL: www.stat.berkeley.edu/ $\sim$ breiman.

Conlon, D. E., \& Murray, N. M. (1996). Customer perceptions of corporate responses to product complaints: The role of explanations. Academy of Management Journal, 39(4), 1040-1056.

Efron, B. (1988). Logistic regression, survival analysis, and the KaplanMeier curve. Journal of the American Statistical Association, 83(402), $414-425$.
Fornell, C., \& Wernerfelt, B. (1987). Defensive marketing strategy by customer complaint management: A theoretical analysis. Journal of Marketing Research, 24, 337-346.

Fornell, C., \& Wernerfelt, B. (1988). A model for customer complaint management. Marketing Science, 7(3), 287-298.

Keaveney, S. M. (1995). Customer switching behavior in service industries: An exploratory study. Journal of Marketing, 59, 71-82.

Kumar, D., \& Westberg, U. (1997). Maintenance scheduling under age replacement policy using proportional hazards model and TTT-plotting. European Journal of Operational Research, 99(3), 507-515.

Larivière, B., \& Van den Poel, D. (2004). Investigating the role of product features in preventing customer churn, by using survival analysis and choice modeling: The case of financial services. Expert Systems with Applications, 27(2), 277-285.

Larivière, B., Van den Poel, D. (2005). Predicting customer retention and profitability by using random forests and regression forests techniques. Expert Systems with Applications, 29(2).

Leeflang, P. S. H., Wittink, D. R., Wedel, M., \& Naert, P. A. (2000). Building models for marketing decisions. Boston/Dordrecht/London: Kluwer.

Levesque, T., \& McDougall, G. H. G. (1996). Determinants of customer satisfaction in retail banking. International Journal of Bank Marketing, 14(7), 12-20.

Maxham, J. G. (2001). Service recovery's influence on consumer satisfaction, positive word-of-mouth, and purchase intentions. Journal of Business Research, 54(1), 11-24.

Maxham, J. G., \& Netemeyer, R. G. (2002). Modeling customer perceptions of complaint handling over time: The effects of perceived justice on satisfaction and intent. Journal of Retailing, 78(4), 239-252.

Maxham, J. G., \& Netemeyer, R. G. (2003). Firms reap what they sow: The effects of shared values and perceived organizational justice on customers' evaluations of complaint handling. Journal of Marketing, $67,46-62$.

Moitra, J. G., \& Lee, T. W. (1993). The regression-analog to survival analysis: A selected application to turnover research. Academy of Management Journal, 36(6), 1430-1464.

Morrow-Howell, N. (1994). The M word: Multicollinearity in multiple regression. Social Work Research, 18(4), 247-262.

Ramlau-Hansen, H. (1983). Smoothing counting process intensities by means of Kernel functions. The Annals of Statistics, 11(2), 453-466.

Singh, J. (1988). Consumer complaint intentions and behaviors: definitional and taxonomical issues. Journal of Marketing, 52(1), 93-107.

Smith, A. K., Bolton, R. N., \& Wagner, J. (1999). A model of customer satisfaction with service encounters involving failure and recovery. Journal of Marketing Research, 36, 356-372.

Stare, J., Harrell, F. E., \& Heinzl, H. (2001). BJ: An S-plus program to fit linear regression models to censored data using the Buckley-James method. Computer Methods and Programs in Biomedicine, 64(1), 45-52.

Stephens, N., \& Gwinner, K. P. (1998). Why don't some people complain? A cognitive-emotive process model of consumer complaint behavior. Journal of the Academy of Marketing Science, 26(3), 172-189.

Tax, S. S., Brown, S. W., \& Chandrashekaran, M. (1998). Customer evaluations of service complaint experiences: Implications for relationship marketing. Journal of Marketing, 62, 60-76.

Therneau, T. M., \& Grambsch, P. M. (2000). Modeling survival data: Extending the cox model. New York: Springer.

Van den Poel, D., \& Larivière, B. (2004). Customer attrition analysis for financial services using proportional hazard models. European Journal of Operational Research, 157(1), 196-217.

Wirtz, J., \& Kum, D. (2004). Consumer cheating on service guarantees. Journal of the Academy of Marketing Science, 32(2), 159-175.

Young, M. R., DeSarbo, W. S., \& Morwitz, V. G. (1998). The stochastic modeling of purchase intentions and behavior. Management Science, 44, 188-202.

Zeithaml, V. A., Berry, L. L., \& Parasuraman, A. (1996). The behavioral consequences of service quality. Journal of Marketing, 60, 31-46. 